DFPARTAMFNTO IOE T'FRAPEUTICA CIANICA

Dluctor: Prof. I)r. Fernando varela de Carvatho

\title{
SÖBRE O MECANISMO DE AÇÃO DO COBALTO NO CORAÇÃO ISOLADO
}

(ON THF: MECHANISM OF ACTION OF COBAIT ION ON THF ISOL ATED HEAR' (.)

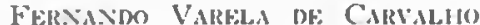
prop. Catedratico

\author{
Stirgio Dr: Mor.lr: \\ prof. Assistente
}

\section{INTROIUCATO}

Fmbora a falência cardiaca scja admitida como causa primária da morte na intoxicação aguda com sais de cobalto $(8,1)$, poucos dados pordem ser coligidos na literatura sôbre o efeito e o mecanismo de ação do metal no coração isolado. KaUf MaÑ e FleckevsTEIN (7) assinalaram (que a adição de cobalto ou níçuel a preparaçōes de músculo papilar isolado de cobaias determina abolição da contratilidade sem redução da excitabilidade, isı é, sem alteração da forma e do valor do potencial de ação do músculo. No mesmo trabalho os autores aventaram a possibilidade do cobalto substituir o cálcio ao nivel da membrana celular, formando um complexo capaz de manter as propriedades biolétricas do músculo cardiaco mas incapa\% de suportar o desenvolvimento de atividade mecânica.

MoraEs e RaMos (4) verificaram que os sais de cobalto produrem falência circulatória aguda em cães, acompanhada por bloqueio A-V e intraventricular. MEDINA (11) verificou consistentes perturbaçōes eletrocardiográficas em cobaias, caracteristicas de anóxia miocárdica.

Neste trabalho estudamos o efeito e o mecanismo de ação do cobalto sôbre o coração isolado visando elucidar alguns aspectos da toxicologia do metal.

\section{MATFRIAL F MFTODOS}

Foram utilizadas 20 cobaias machos e fêmeas, pesando 400$500 \mathrm{~g}$. Os animais foram sacrificados por golpe na nuca e secção dos vasos cervicais. O coração, retirado, foi lavado imediatamente em Ringer-Locke resfriado a $5^{\circ} \mathrm{C}$ e a seguir suspenso pela aorta 
ligada à cânula de vidro. Através da aorta fluia a soluçāo de Ringer-Locke, à pressão de $10-20 \mathrm{~mm} \mathrm{Hg}$, oxigenada e mantida a 37 "C. As drogas foram adicionadas ao líquido de incubaçāo por uma abertura lateral na cânula, próxima ao coração. A extremidade do ventrículo esquerdo foi ligada por um fio de sêda à alavanca inscritora tipo Starling.

Soluçōes e drogas utilizadas: Ringer-Locke (mM) pH 7.4, NaC1 $154.0, \mathrm{KCl} 5.6, \mathrm{CaCl}_{2} 2.2, \mathrm{NaHCO}_{3} 3.6$ e glicose $5.5 \mathrm{O}$ sal de cobalto utilizado foi o $\mathrm{CoCl}_{2}, 6 \mathrm{H}_{2} \mathrm{O}(1 \mathrm{M}, \mathrm{pH} 6.0)$ dissolvido em solução fisiológica. Foram ainda utilizados: $\mathrm{CaCl}_{2}$ (1 M) em solução fisiológica, cloridrato de 1-epinefrina e bitartarato de 1-norepinefrina. As soluções de catecolaminas continham $0.01 \mathrm{M}$ de ácido ascórbico como anti-oxidante e foram conservadas $\mathrm{em}$ banho de gêlo quando em uso. Todos os sais utilizados foram de padrāo analítico. As doses de catecolaminas no texio, referem-se ao sal e são expressas em gramas.

\section{RFSUL'IADOS}

A adição de $0.5 \mathrm{ml}$ de uma solução $1 \mathrm{M}$ de cloreto de cobalto ao líquido de incubação determinou abolição da capacidade contrátil com parada cardíaca em diástole. Os efeitos do metal sôbre as propriedades inotrópica e cronotrópica foram antagonizados pela adição ao líquido nutritivo de $0.5 \mathrm{ml}$ de uma soluçāo $1 \mathrm{M}$ de cloreto de cálcio (figura 1). O antagonismo ionico mostrou-se sempre recíproco e equiimolar (figura 2). A presença de cobalto no meio de incubação provocou supressão da resposta cardiaca a 1-epinefrina e 1-norepinefrina. A adição de cálcio, em concentraçōes insuficientes para antagonizar o efeito do cobalto, determinou recuperação dos efeitos das catecolaminas (figuras 3 e 4 ).

\section{DISCUSSAO}

Os trabalhos básicos de RINGer (12) e DALY e Clark (3) estabeleceram a importância dos cations fisiológicos ( $\mathrm{Na}, \mathrm{K}$ e $\mathrm{Ca}$ ) na manutenção do estado contrátil do coraçāo isolado. Particular atenção despertou o cảlcio pois a fôrça da contração do coração isolado mostrou-se dependente das concentraçōes extracelulares do mesmo $(13,14)$. Alguns autores, recentemente, admitiram ser o cálcio o elo fisiológico fundamental entre os fenômenos elétricos de membrana e a atividade mecânica do coração isolado. O cálcio seria indispensável para a manutençāo da integridade fisiológica do "excitation-contraction coupling" no coraçāo isolado $(15,2,6$, $16,9,10$ ).

GaRB (5) observou que os efeitos do cálcio sôbre a contratilidade do coração isolado são altamente específicos e que sỏmente 
o estrôncio (8) poderia substituir o cálcio adequadamente. NIEDERGERKE (14) sugeriu a presença de receptores específicos para o cálcio ao nivel da superficie externa da membrana celular. A ligaçāo cálcio-sítio receptor hipotético seria representada por uma reaçāo química reversivel.

Baseados no modêlo de antagonismo iônico, no coração isolado, proposto por Niedergerke e LïtTTGAU (13), NiEdergerke (14) e KaUfmann e Fleckenstein (7) poderíamos admitir que o cálcio c o cobalto competiriam em sítios aniônicos bivalentes superficiais. WilbRANDT e KOELLER (17) sugeriram, distribuir-se o cálcio, de acôrdo com o equilíbrio de Donnan, entre o líquido que banha a célula e a camada superficial da membrana. Supondo que a face externa da membrana celular possuisse alta concentração de cargas negativas (poucos anions móveis), a quantidade de cálcio utilizável poderia ser função da concentração extracelular do mesmo. A presença de ions cobalto no meio extracelular, tornaria menor o número de receptores aniônicos bivalentes superficiais, disponiveis para a incorporação do cálcio, diminuindo portanto sua participação, nos processos mantenedores da contração do coração isolado. Esquemàticamente teriamos:

$$
\mathrm{Co}^{++}+\mathrm{CaR} \underset{\mathrm{K}_{2}}{\stackrel{\mathrm{K}_{1}}{\rightleftharpoons}} \mathrm{CoR}+\mathrm{Ca}^{++}
$$

onde CaR é o complexo ativador da contração enquanto CoR é inativo, $K_{1}$ e $K_{2}$ são constantes de velocidade. Admitindo o número total de receptores aniônicos bivalentes superficiais como unitário e supondo que êstes receptores possam ser ocupados pelo cálcio ou pelo cobalto, a aplicação da lei da ação das massas nos daria:

$$
\frac{\left[\mathrm{Ca}^{++}\right]}{\left.\mid \mathrm{Co}^{++}\right]}=\frac{\mathrm{K}_{1}[\mathrm{CaR}]}{\mathrm{K}_{2}[1-\mathrm{CaR} \mid}
$$

Portanto a concentração do complexo ativador CaR depende do quociente $\left.\mid \mathrm{Ca}^{++}\right\rfloor$e não especialmetne das concentrações iônicas $\left[\mathrm{Co}^{++}\right]$absolutas.

Nossos resultados experimentais suportam a hipótese de que, no coração isolado, o cobalto produziria seus efeitos antepondo-se ao aproveitamento fisiológico do cálcio, indispensável para preservação da atividade contrátil do coração isolado.

\section{SUMMARY}

The effects of cobalt ion on the isolated heart of the guinea-pig were studied. The addition of cobalt to the incubation medium ceases the contractions of the isolated heart. The effect of cobalt 
ion could be prevented by the addition to the incubation medium of calcium ion in equimolar concentrations. Cobalt ion prevented the effects of 1-epinephrine and 1-norepinephrine and these effects of the cation, were antagonized by the presence of calcium ion in amounts not sufficient to antagonize completely the effects of cobalt ion. The mechanism of action of cobalt ions on the isolated heart was discussed. It was proposed that cobalt ion prevents the utilization of calcium ion in the physiological process supporting the mechanical activity of the isolated heart.

\section{RFFERÊNCIAS IBIBI,IOGRÁFICAS}

1. IBARTHLHF:INFR, F. W. - Analyse der akuten kobaltrergiftung in tierversuch. Arch. exp. Path. Phulmk., 2/3:237-253, 1962.

2. IBRADY, J. - Fxcitation and excitalion-contraction coupling in cardiac muscle. Am. Rev. Physiol., 26:231-256, 1964.

3. DAIY, I. de B. \& CLARK, A. J. 'The action of ions upon the frog's he'art. J. Physiol., London, 54:367-383, 1921.

4. MORAl:S. S. \& RAMOS. A. O. - Vecanismos contrais na genese dos efeitos periféricos obtidos com a injecão de cobalto. Ler. Fur. Furm. Bioq. S. Paulo, 4:225-237, 1966.

5. GARB, S. - The offects of potassium, ammonium, calcium, strontium and magnesium on the electrogram and myogram of mammalian heart muscke. J. Phormurol. exp. Ther., 101:317-326, 1951.

6. HUXLFY, A. F. - Muscle. Ann. Rev. Physiol., 26:131-152, 1964.

7. KAUFMANN, R. \& FI.FCKLNSTEIN, A. - Cat+-kompetitive elektromecanishe lintkoppelung durch $\mathrm{Ni}_{+}^{+}$und $\mathrm{Co}^{+}+\ldots$ Ionen am Warmblütermyokard. Pflïger Arch. Ges. Physiol., $282: 290-297,1965$.

8. LAMARCHE, M. \& KOCAREV, R. - Action du chlorure de cobalt sur la pression arteriélle du cobaye. C. R. Sor. Biol., Paris, 15/:363-365. 19.37.

9. I.EF, Y. C. P.; RICIIMAN, H. G.; VISCHF, N. B. - Fixtracellulal calcium ion and reversible cardiac arrest. Amer. J. Physiol., 210:493$198,1966$.

10. - - - $\left[\mathrm{Ca}^{-+}+\right]$and $[\mathrm{K} \cdot]$ interrelations influencing mechanical and clectrical events in cardiac activity. Ibid., $210: 499-504$, 1966.

11. Mi.pINA. H. S. G. - Comunicação pessoal, 1969.

12. RINGER, $S$. - A further contribution regarding the influence of the different constituints of the blood on the contraction of the heart. $J$. Physiol., London, 4:29-47, 1833. "Apud" Niedergerke, R. - J. Physiol., I ondon, $167: 515-550,1963$.

13. NIEDERGERKF, R. \& LÜTYGAU, H. C. - Calcium and the contraction of the heart. Antagonism between calcium and sodium ions. Nature. I ondon, $1 \% 9: 1066-1067,1957$. 
14. NIEDFRGERKF; R. - Movements of $\mathrm{Ca}$ in frog heart ventricles at rest and during contractures. J. Physiol., London, 16\%:515-550, 1963.

15. SANDOW, A. - Excitation-contraction coupling in muscular response. Yale J. Biol. Med., 25:176-201, 1952.

16. WALKER, J. M. G. \& WEATHFRALL, M. - Calcium in relation to the action of ouabain and adrenalin. Br.J. Phurmucol. Chemother, 2.3: $66-79,1964$.

17. WII.BRANDT, W. \& KOHI.I.ER, H. - Die Calcium Wirkung am Froschhersen als Funktion des Ionengleichgewitz Swischen Zellmembran und L'mgebung. Helr. Physiol. Phurmurol. Actu., 6:208-221, 1948. 


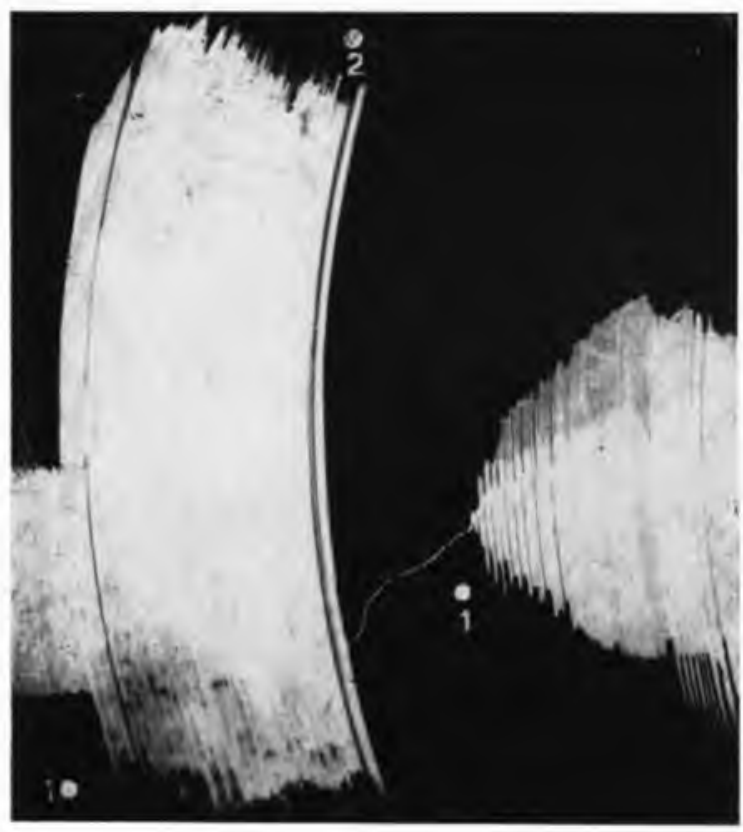

Fig. 1 - Antagonismo entre cálcio e cobalto. Coraç̃o isolado de cobaia em Ringer-L_ock, temperatura $37^{\circ} \mathrm{C}$. Da esquerda para a direita: 1) adiç̆o de $0.5 \mathrm{ml}$ de um solucão de cloreto de cálcio ( $1 \mathrm{M}$ ), em 2) adição de $0.5 \mathrm{ml}$ de uma solucão de thoreto de cobalto ( $1 \mathrm{M}$ ). Números Iguais indicam a adicảo da mesma droga em concentracões iguais.

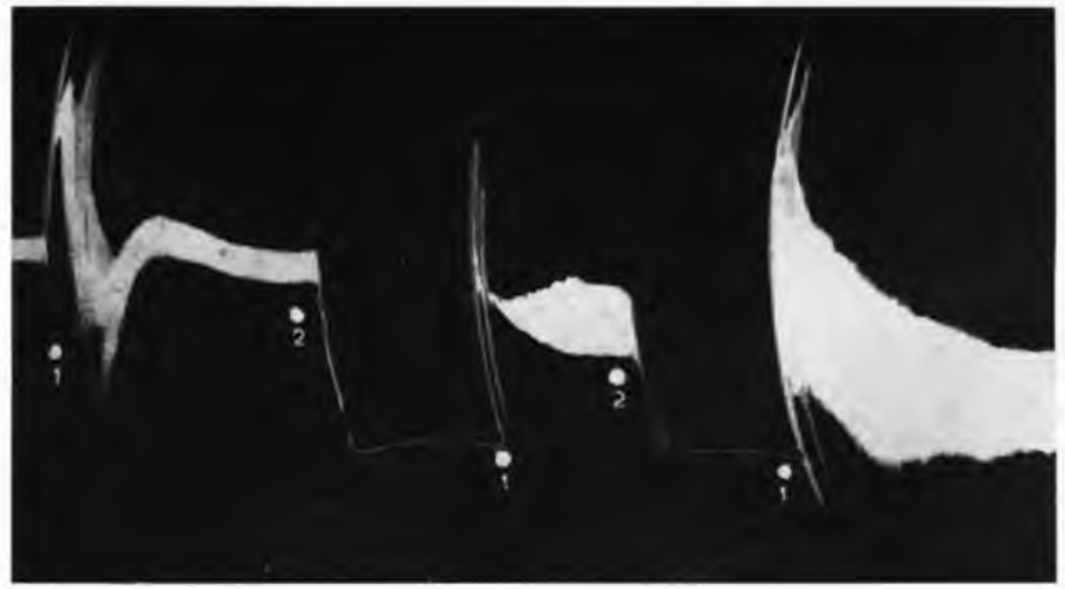

Fig. 2 - Antagonismo entre cálcio e cobalto. Coracūo isolado de cobaia em linger-Locke, temperatura $37^{\circ} \mathrm{C}$. Da esquerda para a direita: 1 a adicáo de $0.3 \mathrm{ml}$ de cloreto de cálcio (1 $\mathrm{M})$, em 2 ) adicão de $0.3 \mathrm{ml}$ de uma solução de ('loreto de cobalto $(1) \mathrm{M})$. Parada rardiaca em diástole. Números iguais indicam a adicảo da mesma droga em concentracões iguais. 


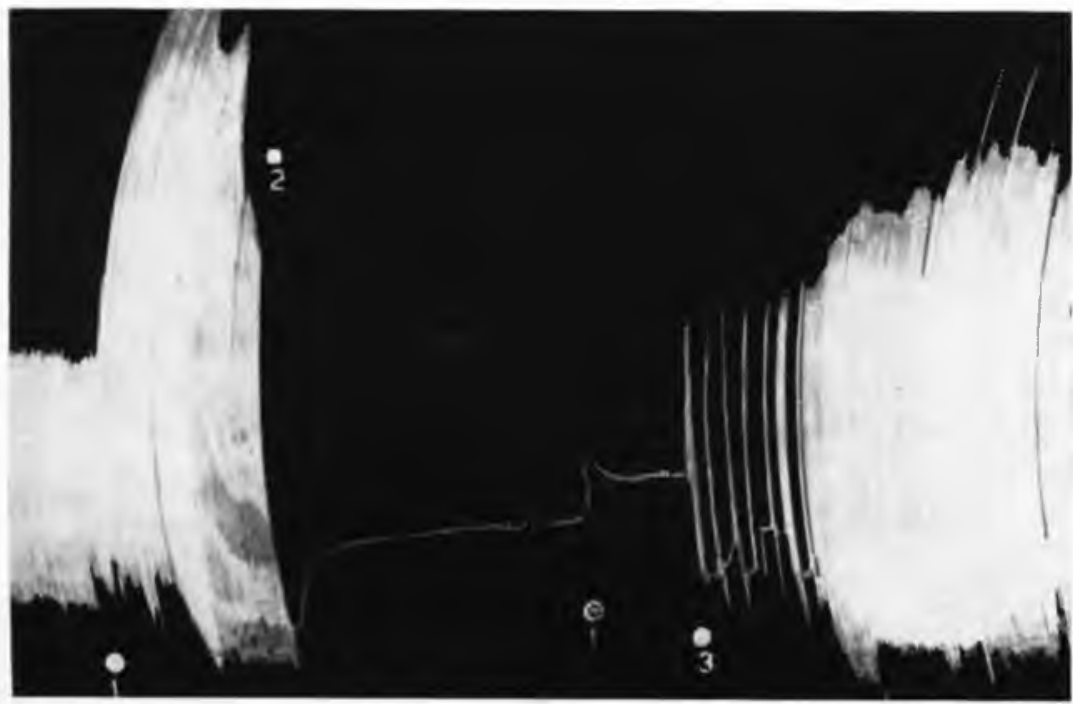

Fig. 3 - Antagonismo entre epinefrina e cobalto. Coraça Isolado de ('obata em lkinger-locke, temperatura $37^{\circ} \mathrm{C}$. Da esquerda para a direita: 1) adicão de $5 \times 10)^{n}$ de epinefrina $(0.2 \mathrm{ml}$ ), em 2) adicăo de $0.5 \mathrm{ml}$ de cloreto de cobalto (1 M). Em 3 ) adicáo de $0.2 \mathrm{ml}$ de cloreco de cálcio (1 M). Notar a lecuperacão parcial do efeito da epinefrina Numeros iguais indicam adição da mesma droğa em concentracôes lguais.

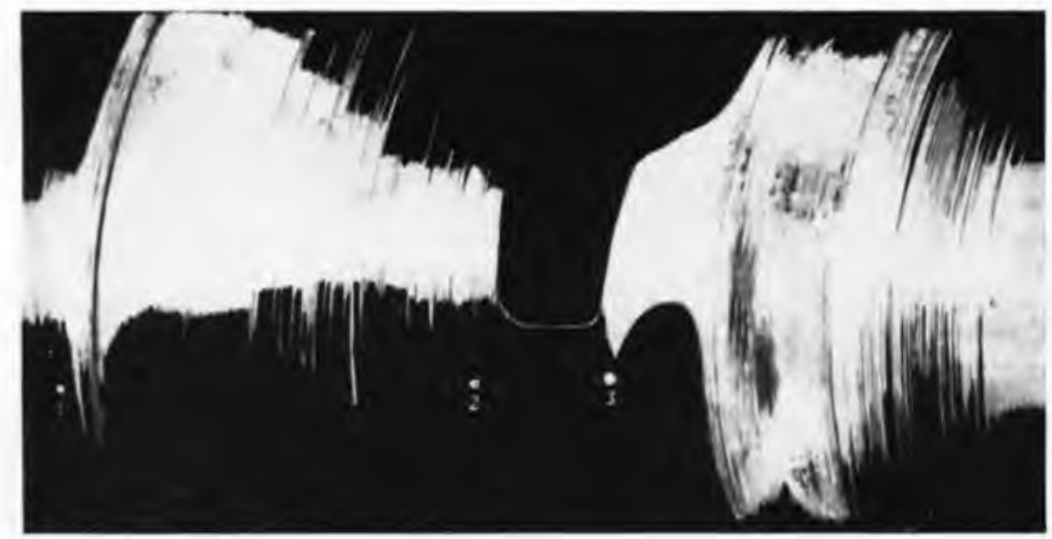

Fig. 1 - Antagonismo entre norepinefrina e cobalto Coraço isolacto de cobala em Ringer-locke, temperatura $37^{\circ} \mathrm{C}$. Da esquerda para a direita: 1) adiceāo de $3 \times 10$-" de norepinefrina $(0.2 \mathrm{ml})$, em 2) adiçâa de $0.5 \mathrm{ml}$ de cloreto de cobalto $(1 \mathrm{M})$. Fim 3 ) adicão simultanca de $3 \times 10-6$ de norepinefrina $(0.2 \mathrm{ml})$ e $0.1 \mathrm{ml}$ de cloreto de cáléo $11 \mathrm{M}$ ) Recuperacăo completa do efeito da norepinefrina 